\title{
A Study of the Intention of Tourists Who Visiting Sanyi Painting
}

\author{
Kuo-Chung Huang \\ Professor \\ Department of Business Administration \\ Nanhua University, Chiayi, Taiwan \\ Mei-Li Yang \\ Ph.D. Student \\ Department of Business Administration \\ Nanhua University, Chiayi, Taiwan
}

\begin{abstract}
For understanding the intention of tourists who visit Sanyi painting, this research applies the theory of planned behavior to study the tourists' intentions and opinions. The questionnaire was distributed and collected in front of the Sanyi Painting Ladder. The results indicate that the tourists' attitudes, subjective norms, and perceived behavioral control had positive effect on their intention respectively. Attitudes have the most significant impact on intention. The construct of attitudes and perceived behavior control have partial mediation effect on the subjective norms to the intention. According to semi-structure questions result, increasing painting areas and to repairing the picture could help with sustainable tourism development of the community.
\end{abstract}

Keywords: Comprehensive Community Development, Sanyi Painting, Painting Village, Theory of Planned Behavior, Intention.

\section{Introduction}

For promoting comprehensive community development, many communities have created painting spots through artistic creation in Taiwan. Sanyi township is in the southern part of Miaoli, a county located in the mountains of northwestern of Taiwan. Sanyi was certificated as cittaslow in 2016 and received lots of reputation in the world.

The painter used interactive composition skill to present different styles and interesting local landmark, which have also given a new vitality to the old street and the community in Sanyi. Meanwhile, they have attracted tourists successfully and made the mountain community become lively and energetic. Taiwanese people are so crazy that will rush for the queue, as well as painted village. Many painted villages in Taiwan are facing decline of tourists' number after the completion of paintings. Moreover, the color of the paintings often fades with time because of the environment.

The number of tourists visiting the Sanyi painting has also been declining. How to promote the village paintings has become an important issue to the Sanyi township and all the residents. Many scholars have pointed out that trying to understand the intentions of visit, as well as providing friendly and convenient services, can attract and maintain existing customers and develop potential ones. At the same time, it affects visitors' willingness to revisit or recommend the benefits to others(Brady \& Cronin, 2001; Kim, Ferrin, \& Rao, 2009).

The theory of planned behavior proposed by Ajzen (1985) is a theory derived from rational behavior theory and mainly used to explain and predict people's behavior. The theory of planned behavior indicated that the intentions were influenced by attitudes, subjective norms, and perceived behavioral control.

According to the theory of planned behavior, the purpose of this research is to investigate the tourists' intention of visiting the Sanyi painting. The results could help the Sanyi township planning the comprehensive community development in the future, and reducing obstruction of visiting, furthermore helping the sustainable tourism development of the cittaslow.

\section{Literature Review}

\subsection{Comprehensive Community Development}

The White Paper on Cultural Affairs reported by Department of Council for Cultural Affairs, Executive Yuan (2004), the authorities present the comprehensive community development topic and indicate the purpose of the policy. 
The first stage, in order to raise peoples' community awareness, to regain people's sense of identity in their own communities, and to jointly improve the quality of community life, the government needs to encourage the residents to participate in comprehensive community development. The comprehensive community development emphasize the concept of cultivation and training to improve life quality and encourage more residents being concerned with their hometown through cultural life circuit in the second stage (Wang, 2016).Ministry of Culture(2015) present the third stage (2016-2021) of community empowerment to establish cultural citizen society and to narrow the gap of cultural resource between urban and rural area. Many communities have begun the plan to promote comprehensive community development, and political support from the government has become an important thrust of community development in Taiwan. Scholars have indicated that the purpose of comprehensive community development is to promote and to improve local cultural environment of communities. Therefore, it is necessary to formulate and implement strategies according to the characteristics of communities themselves, such as improving the living environment of the communities, preserving local cultural or historical materials like monuments, or promoting community arts and cultural activities. Besides local township, it is also necessary for the residents and other organizations to participate in comprehensive community development (Chang, 2012; Chang, 2015; Chao, 2015; Chu, Tseng \&Sheu, 2006; Hsieh, 2017; $\mathrm{Wu}, 2003)$. The vitality of the community could be improved through the participation of the residents. In additional, the new image of township attracts tourists' visiting and creates business opportunity as well.

\subsection{Sanyi Painting}

Sanyi is a typical mountain township and the majority are Hakka people. The residents depend mainly on wood carving for their livelihoods, so the community is a traditional rural settlement. Former township mayor Wen Ta Hsu worried that people are forgetting the prosperous situation of main street in downtown and Hakka people's multidimension culture. Therefore, he built the blueprint of community development project, including village painting and pursuing the support from the authority. Fortunately, Sanyi township got the subsidy and accomplished the 99-stage ladder painting and wall paintings which exhibit the Tung flower, leopard cat, railway culture, wood carving, Long-Teng bridge, and Hakka culture image of the community.

\subsection{Theory of Planned Behavior}

The theory of planned behavior indicated that determinant behavior is one's intention to engage in that behavior. The intention is determined by three constructs: attitudes toward the behavior, subjective norms, and perceived behavioral control (Ajzen, 1991). As a general rule, the more favorable the attitudes and subjective norms, and the greater the perceived behavioral control, the stronger should be the person's intention to perform the concerned behavior (Ajzen, 2006). In this research, the construct of "attitudes" is defined as assessing the cognition of the tourists about the feelings of visiting Sanyi painting, and "subjective norms" is defined as considering how the tourists' family, relatives, friends and others influence on their visits to village paintings locations. And "perceived behavioral control" is defined as evaluating how well the tourists have cognition of their ability to handle their time, energy, and transportation.

\section{Methodology}

\subsection{Research Model and Hypotheses}

In this study, exploring the tourists' behavior and intention, the framework is considered and built basically.

\section{Figure 1 research model}

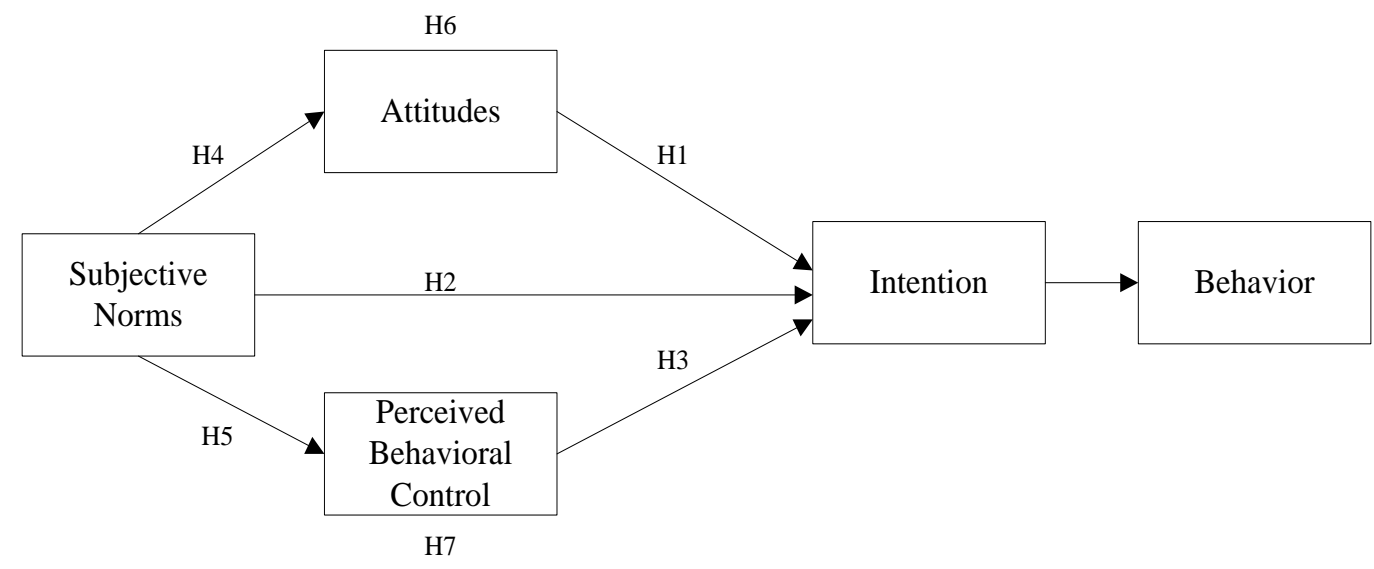

According to the framework, seven hypotheses are listed as follows: 
H1. Attitudes of the tourists have played a positive role in affecting the tourists' intention to visit Sanyi painting.

H2. Subjective norms of the tourists have played a positive role in affecting the tourists' intention to visit Sanyi painting.

H3. Perceived behavioral control of the tourists have played a positive role in affecting the tourists' intention to visit Sanyi painting.

H4. Subjective norms of the tourists have played a positive role in affecting the tourists' attitudes.

H5. Subjective norms of the tourists have played a positive role in affecting the tourists' perceived behavioral control.

H6. Attitudes of the tourists have a mediation effect between tourists' subjective norms and the intention.

H7. Perceived behavioral control of the tourists have a mediation effect between tourists' subjective norms and the intention.

\subsection{Questionnaire Design}

In this study, based on the relevant literature and suggestion from former township mayor Wen Ta Hsu, we tried to find multiple tourism dimensions. The data collected has content validity. Four constructs were contained in this questionnaire. In the construct of "Attitudes", nine items were designed based on four studies (Ajzen, 1991; Blackwell, Engel \&Miniard, 2012; Chu, Tseng \& Sheu, 2006; Hsu, Yeh \& Lin, 2012). In the construct of "Subjective norms", four items were designed based on the works done by some scholars (Ajzen, 1991;Hsieh, Huang \& Hsu 2017; Lin \& Hsieh, 2005; Schiffman \&Kanuk, 2000).Four items in the construct of "Perceived behavior control" were designed based on four studies (Ajzen, 1991; Hsieh, Huang \&Hsu, 2017; Taylor \& Todd, 1995;Wang, 2016). Five items in the construct of "Intention" were designed based on the works by some scholars (Ajzen, 1991;Kuo, 2008; Zeithaml, Berry \& Parasuraman, 1996).The original questionnaire items apply the five-point Likert-type scale to indicate the tourists' agreement or disagreement with the items. The level of agreements in the Likert-type scale utilized responses from 1 to 5, where 1: Strongly Disagree; 2: Disagree; 3: Neither Agree nor Disagree; 4: Agree; 5: Strongly Agree. Meanwhile, the content of the questionnaire also included the source of the tourists, gender, age, marital status, education level, number of visits, and transportation method, to collect the demographic information. Additionally, in order to understand the tourists' experience of visiting the painting villages and their suggestions to the township, there were three semi-structure questions including "Your suggestion after explore Sanyi painting", "Have you visited other painting villages in Taiwan in addition to Sanyi painting" and "Where are you from". In assessing the reliability of the questionnaire, the Cronbach's alpha was checked. According to Nunnally (1978), standard Cronbach's alpha should be greater than 0.5 , with a coefficient alpha above 0.7 is preferred. Regarding to its satisfying internal consistency, in this study, the coefficient alpha of four construct were all above 0.8 , showing that the questionnaires had high reliability.

\subsection{DataCollection}

The acquisition of questionnaires was distributed to collect opinions of tourists who visited Sanyi painting, and altogether 226 tourists were recruited and finally 198 valid data were collected in this research.

\section{Analysis and Discussion}

\subsection{Demographic Information}

In this study, 198 valid data were collected finally. 40.9 percent of the respondents were male and $71.7 \%$ were above 25 years old. 51.5percent of the respondents were married and56.6\%of the respondents' educational level have above college. 57.6 percent responded that it was their first time visiting the Sanyi painting. $62.6 \%$ tourists drive by themselves, and 5.6\% with public transportation tools. Only 34.3 percent of tourists know Sanyi township is the slow city. Detailed statistics related to the respondents' characteristics were shown in Table 1. 
Table 1. Demographic Information

\begin{tabular}{|c|c|c|c|}
\hline Item & Answering Options & Frequency & Percent \\
\hline \multirow[t]{2}{*}{ Gender } & Male & 81 & 40.9 \\
\hline & Female & 117 & 59.1 \\
\hline \multirow[t]{6}{*}{ Age } & $\leqq 24$ years & 56 & 28.3 \\
\hline & 25-34years & 45 & 22.7 \\
\hline & 35-44years & 50 & 25.3 \\
\hline & 45-54years & 32 & 16.2 \\
\hline & 55-64years & 11 & 5.6 \\
\hline & $\geqq 65$ years & 4 & 2 \\
\hline \multirow[t]{4}{*}{ Marital status } & Single & 96 & 48.5 \\
\hline & Married without children & 30 & 15.2 \\
\hline & Married with children & 67 & 33.8 \\
\hline & Divorce & 5 & 2.5 \\
\hline \multirow[t]{5}{*}{ Education } & Elementary School & 3 & 1.5 \\
\hline & Junior high School & 43 & 21.7 \\
\hline & Senior high School & 40 & 20.2 \\
\hline & College & 92 & 46.5 \\
\hline & Graduate School & 20 & 10.1 \\
\hline \multirow[t]{4}{*}{ Number of visits } & First time & 114 & 57.6 \\
\hline & $2-3$ times & 27 & 13.6 \\
\hline & $4-5$ times & 7 & 3.5 \\
\hline & Above 5 times & 50 & 25.3 \\
\hline \multirow{4}{*}{$\begin{array}{l}\text { Transportation of go } \\
\text { back and forth }\end{array}$} & Public Transportation & 11 & 5.6 \\
\hline & Tour bus & 21 & 10.6 \\
\hline & Drive by yourself & 124 & 62.6 \\
\hline & Others & 42 & 21.2 \\
\hline
\end{tabular}

\subsection{Factor Analysis and Reliability Analysis}

According to Table 2, it indicates that in this study, KMO values of attitudes, subjective norms, perceived behavioral control, and intention are respectively given by $0.911,0.685,0.758$ and 0.824 , each construct's KMO value is greater than0.6, and each construct's Bartlett's test of sphericity is significant, implying that the data are appropriate for factor analysis.

Table 2. KMO Value and Bartlett's Test of Sphericity for Each Construct

\begin{tabular}{lcccc}
\hline \multirow{2}{*}{ Construct } & \multirow{2}{*}{ KMO value } & \multicolumn{3}{c}{ Bartlett test of sphericity } \\
\cline { 3 - 5 } & & Chi-square & df & Sig.(2-tailed) \\
\hline Attitudes & 0.911 & 1331.601 & 36 & $0.000^{* * *}$ \\
Subjective Norms & 0.685 & 626.548 & 6 & $0.000^{* * *}$ \\
Perceived Behavioral Control & 0.758 & 306.654 & 6 & $0.000^{* * *}$ \\
Intention & 0.824 & 614.523 & 10 & $0.000^{* * *}$ \\
\hline
\end{tabular}

$* \mathrm{p}<0.05, * * \mathrm{p}<0.01, * * * \mathrm{p}<0.001$

The results of factor analysis for each construct were shown in Table 3. All the items' factor loadings are greater than 0.5 , with the percentage of variance respectively given by64.103\%,75.413\%,66.040\%, $70.547 \%$. No item should be deleted. To examine the reliability, all the values of Cronbach's alpha were greater than 0.7 , implying a high degree of internal consistency.

Table 3. Results of Factor Analysis and Reliability Analysis

\begin{tabular}{lccc}
\hline \multicolumn{1}{c}{ Construct } & Factor Loading & $\begin{array}{c}\% \text { of } \\
\text { Variance }\end{array}$ & Cronbach's Alpha \\
\hline Attitudes & $0.546-0.889$ & 64.103 & 0.917 \\
Subjective Norms & $0.803-0.911$ & 75.413 & 0.885 \\
Perceived Behavioral Control & $0.763-0.855$ & 66.040 & 0.827 \\
Intention & $0.755-0.880$ & 70.547 & 0.890 \\
\hline
\end{tabular}


Related to attitudes, tourists express high interests in taking photos and that makes them happy. Related to subjective norms, the highest influencing factor is that "I accept my friend's recommendation". In addition, television news or program report and Internet discussion affect whether tourists want to visit the destination afterwards. Related to perceived behavioral control, tourists indicate that they have enough time and energy to appreciate the 99-stage ladder painting, which is the most eye-catching spot of Sanyi painting.

\subsection{Means Analysis}

Independent samples $\mathrm{T}$ test was adapted to gender, and for the other demographic items, one-way ANOVA with Scheffe's test of post-hoc comparisons were conducted, which indicate whether the demographic characteristics were very importantly different in statistics for each construct. For understanding tourists' intention through Means Analysis, the results were shown that among the six demographic items, there is no different of intention among attitudes, subjective norms and perceived behavioral control.

\subsection{Regression Analysis}

Based on linear regression, as Table 4 showed the results, the standardized regression coefficient of the construct of attitudes, subjective norms and perceived behavioral control to intention were $0.786,0.772$ and 0.761 respectively. All the results were statistically significant. According to multiple regression, attitudes, subjective norms and perceived behavioral control were statistically significant, and therefore the hypothesis of $\mathrm{H} 1 \sim \mathrm{H} 3$ could not be rejected. As a result, the tourists' attitudes, subjective norms and perceived behavioral control positively affect the intention of visit the paintings of Sanyi. In particular, attitudes has greater effect on tourists' intention than the perceived behavioral control, toward the behavior and subjective norms.

Table 4. Regression Analysis

\begin{tabular}{lllll}
\hline \multicolumn{1}{c}{ Dependent Variable } & Intention & Intention & Intention & Intention \\
Independent Variable & & & \\
\hline Attitudes & $0.786^{* * *}$ & & & \\
Subjective Norms & & $0.772^{* * *}$ & & $0.363^{* * * *}$ \\
Perceived Behavioral Control & & & $0.761^{* * *}$ & $0.348^{* * *}$ \\
$\mathrm{R}$ & 0.786 & 0.772 & 0.761 & 0.864 \\
$\mathrm{R}^{2}$ & 0.617 & 0.595 & 0.579 & 0.747 \\
adj . $\mathrm{R}^{2}$ & 0.615 & 0.593 & 0.577 & 0.743 \\
F-value & 316.329 & 288.432 & 269.948 & 190.891 \\
\hline $\mathrm{p}<0.05, * * \mathrm{p}<0.01, * * * \mathrm{p}<0.001$ & & & &
\end{tabular}

Mediation effect of attitudes was examined with respect to criterion proposed by Baron and Kenny (1986). Compare the results given in model 2 and model 4 in Table5, the standardized regression coefficient of subjective norms decreased from 0.772 to 0.441 , after adding attitudes in regression model. Attitudes was still significantly positive effect on intention in model 4. As a result, the tourists' attitudes has a partial mediation effect on the relationships between subjective norms and intention. Hence, the hypotheses of $\mathrm{H} 4$ and $\mathrm{H} 6$ were not rejected.

Table 5. Mediation Effect Analysis (Mediator: Attitudes)

\begin{tabular}{|c|c|c|c|c|}
\hline Dependent Variable & Attitudes & Intention & Intention & Intention \\
\hline Subjective norms & $\begin{array}{l}\text { Model 1 } \\
0.681 * * *\end{array}$ & $\begin{array}{l}\text { Model 2 } \\
0.772 * * *\end{array}$ & Model 3 & $\begin{array}{l}\text { Model } 4 \\
0.441^{* * *}\end{array}$ \\
\hline Attitudes & & & $0.786 * * *$ & $0.485^{* * *}$ \\
\hline $\mathrm{R}$ & 0.681 & 0.772 & 0.786 & 0.849 \\
\hline $\mathrm{R}^{2}$ & 0.464 & 0.595 & 0.617 & 0.722 \\
\hline $\operatorname{adj} . R^{2}$ & 0.461 & 0.593 & 0.615 & 0.719 \\
\hline F-value & 169.803 & 288.432 & 316.629 & 252.735 \\
\hline
\end{tabular}

Mediation effect of perceived behavioral control on the relationships between attitudes toward the behavior and intention was found through analysis. Compare the results given in model 2 and model 4 in Table 6, the standardized regression coefficient of subjective norms decreased from 0.772 to 0.469 , after adding perceived behavioral control in regression model. 
Attitudes toward the behavior was not significantly positively effect on intention in model 4 . As a result, the perceived behavioral control has a partial mediation effect on the relationships between subjective norms and intention. Hence, the hypotheses of $\mathrm{H} 5$ and $\mathrm{H} 7$ were not rejected.

Table 6. Mediation Effect Analysis (Mediator: Perceived Behavioral Control)

\begin{tabular}{lllll}
\hline \multicolumn{1}{c}{ Dependent Variable } & $\begin{array}{l}\text { Perceived } \\
\text { Behavioral } \\
\text { Control }\end{array}$ & Intention & Intention & Intention \\
& Model 1 & Model 2 & Model 3 & Model 4 \\
\hline Subjective norms & $0.695^{* * *}$ & $0.772^{* * *}$ & & $0.469^{* * *}$ \\
Perceived Behavioral Control & & & $0.761^{* * *}$ & $0.435^{* * *}$ \\
$\mathrm{R}$ & 0.695 & 0.772 & 0.761 & 0.833 \\
$\mathrm{R}^{2}$ & 0.483 & 0.595 & 0.579 & 0.693 \\
adj . $\mathrm{R}^{2}$ & 0.480 & 0.593 & 0.577 & 0.690 \\
$\mathrm{~F}-\mathrm{value}$ & 182.811 & 288.432 & 269.948 & 220.447 \\
$* \mathrm{p}<0.05, * * \mathrm{p}<0.01, * * * \mathrm{p}<0.001$ & & & &
\end{tabular}

\section{Conclusions}

The results of factor analysis, reliability analysis and regression analysis in this research show that the standardized regression coefficient of each constructs to intention from the highest to the lowest were attitudes, subjective norms, and perceived behavioral control. The standardized regression coefficient was respectively given by $0.786,0.772,0.761$, showing that the attitudes was the most important construct influencing the tourists' intention to visit the Sanyi painting. We could tell the tourists' cognition that visiting the painting village can relieve the pressure in life, create the happy moods, and increase the time being with family or friends. The construct of subjective norms indicated that friends and family would influence the tourists' intention to visit the Sanyi painting. Furthermore, the reports by mass media and online referrals would influence tourists' intention to visit. The construct of intention showed that if the tourists were satisfied with this journey, they would be willing to visit again, to recommend the painting villages to their relatives and friends, and to recommend the tour destination on the Internet. The suggestions from important people as well as the reports by mass media and online referrals have positive influence on the tourists' willingness of visiting. The results of semi-structure questions showed that most of the tourists visit other painting villages in additions Sanyi, such as the paintings " Rainbow Village" in Taichung, "Cat world" in Chiayi and so on. In other words, tourists would like to visit painting villages if they are available. The tourists also suggested that improvement of hardware construction, including handrail, chair, rest areas, guiding signs and so on is needed. Since most of the tourists do not know Sanyi is a cittaslow, it is necessary to do the promotion of the township and create issue which could help with tourists knowledge of Sanyi painting and its distinctiveness.

\section{References}

Ajzen, I. (1985). From intention to action: A theory of planned behavior. In J. Kuhl, \& J. Beckmann (Eds.), Actioncontrol: From cognition to behavior (pp. 11-39). New York: Springer-Verlag

Ajzen, I. (1991). The theory of planned behavior. Organizational Behavior and Human Decision Processes, 50, 179211.

Ajzen, I. (2006). Constructing a TpB Questionnaire: Conceptual and Methodological Considerations. [Online] Available: https://pdfs.semanticscholar.org/0574/b20bd 58130dd5a961f1a2db10fd1fcbae95d.pdf(October 1, 2018)

Ajzen, I., \& Madden, T. J. (1986). Prediction of goal directed behavior: Attitudes, intentions, and perceived behavioral control. Journal of Experimental Social Psychology, 22(5), 453-474.

Blackwell, R. D., Miniard, P.W., \& Engel J. F. (2012). Consumer behavior. Singapore: Cengage Learning Asia, (Chapter 8).

Baron, R. M., \& Kenny, D. A. (1986). The moderator-mediator variable distinction in social psychological research: Conceptual, strategic and statistical considerations. Journal of Personality and Social Psychology, 51(6), 11731182.

Brady, M. K., \& Cronin, J. J. J. (2001). Customer orientation: Effects on customers service perceptions and outcome behaviors, Journal of Service Research, 3(3), 241.

Chang, L. Y. (2015). The Governance Predicament and Construction Strategies of Sustainable Community. The Degree of Doctor of Philosophy in Department Public Policy and Administration, National Chi Na University. 
Chang, Y. C. (2012).Tourism Development in the Context of Community Empowerment: A Tourism Anthropological Analysis on the Fengtian Community in Hualien. The Degree of Doctor of Philosophy in Institute of Anthropological, Tsing-Hua University.

Chao, Chi-Ming, Huang, \&Wei-Ting (2015) Painted Research Community Loving Environment and Tourism - Taking Huwei Township Top Brook Case. Journal of Cultural Enterprise and Management, 13, 57-72.

Chu, Li-Chuan, Tseng, Hsiu-mi \& Sheu, Kuen-Feng(2006) Residents' Expectation in Community Empowerment Regarding the Role of Community Builders. Journal of Environment and Management, 7(1), 48-67.

Department of Council for Cultural Affairs, Executive Yuan (2018). The White Paper on Cultural Affairs [Online] Available:http://mocfile.moc.gov.tw/mochistory/images/policy/2004white_book/index.htm (March 26, 2018)

Hsieh, C. L. (2017) A Study on the Evaluation Model of Sustainable Management Strategy of Cultural. The Degree of Doctor of Philosophy in Management, College of Management, National Taipei University of Technology.

Hsieh, L. Y., Huang, C. Y.,\& Hsu, M. C. (2017) Empirical Study on Tourist Behavioral Intentional Pattern of LiuDui Hakka Cultural Centre. Journal of Sport and Recreation Management, 14(2),1-12.

Hsu, M. C., Yeh, M. J.,\& Lin, Y. H. (2012) A Study on Tourists Traveling Behavior Intention Model in Dapeng Bay National Scenic Area- The Verification of Theory of Planned Behavior. Leisure \& Society Research, 6, 1-25.

Kim, D. J., Ferrin, D.L., \& Rao, H. R. (2009). Trust and satisfaction, two stepping stones for successful e-commerce relationships: A longitudinal exploration. Information Systems Research, 20(2), 237-257. DOI: 10.1287/isre.1080.0188

Kuo, C. J. (2008) The Study of Community Residents' Participation Behavior Model in Environmental Improvement Actions. The Degree of Doctor of Philosophy in Public Affairs Management, National Sun Yat-Sen University.

Lin, Min-Ray \& Hsieh, Yu-Chih (2005) A study on the Developmental Factors of Model Environmental Communities in Central Taiwan. Journal of National Taichung Teachers College. 19(1), 89-113.

Ministry of Culture (2018), Community Taiwan [Online] Available: https://community taiwan.moc.gov.tw/ (September 27, 2018)

Schiffman, L. G., \& Kanuk, L. L. (2000). Consumer behavior (7th ed.). Upper Saddler River, NJ: Prentice Hall.

Taylor, S., \& Todd, P. (1995). Decomposition and crossover effects in the theory of planned behavior: A study of consumer adoption intentions. International Journal of Research in Marketing, 12(2), 137-155.

Wang, B. C. (2016) Discussing the Composition of the Cultural Life Circuit through the Local Development ProcessA Case Study of Da-si Village, Miaoli County Journal of Architecture, 96 109-124.

Wu, Tsung-Chiung(2003) Analyzing Impact Cognitions of Tribe Tourism Development - From the Perspectives of Resident's Participation and Tourism Development Stages. Bulletin of the Geographical Society of China. 31, 13-30.

Zeithaml, V. A., Berry, L. L., \& Parasuraman, A. (1996). The behavioral consequences of service quality. Journal of Marketing, 60(2), 31-46. 